\title{
Eles são assim: racismo e o terremoto de 12 de janeiro de 2010 no Haiti ${ }^{1}$
}

\author{
OMAR Ribeiro Thomaz
}

\begin{abstract}
Para Guy Dallemand
Não pude dissimular. Meu espírito ficou em estado de choque quando lia diversas obras onde se afirmava dogmaticamente a desigualdade das raças humanas e a inferioridade nativa dos negros. (Antenor Firmin, pensador haitiano, pai da antropologia moderna, 1885).
\end{abstract}

\section{I - Revoluçóes e terremotos}

Em 2010 foi dado o início às celebrações das independências hispano-americanas. Entre 19 de abril de 1810 (Venezuela) e 27 de setembro de 1821 (México), o Império Espanhol na América se desagrega, permanecendo sob o poder de Madri apenas duas ilhas caribenhas, Cuba e Porto Rico. Independências no entremeio de outras duas, diametralmente opostas: a do Haiti, no dia $1^{\circ}$ de janeiro de 1804 , e a do Brasil, no dia 7 de setembro de 1822 . Independências estruturalmente opostas, pois a primeira supôs efetivamente uma revolução certamente a única das Américas - e a segunda a forma mais descarada de interiorização da metrópole, manutenção do status quo das elites locais e, sobretudo, da escravidão e do tráfico negreiro. É desconfortável, mas nada surpreendente, o esquecimento da independência do Haiti. Desconfortável, pois já é hora da revolução haitiana ser incorporada entre os grandes eventos da história universal; nada surpreendente, pois o pensamento dito ocidental nunca foi capaz de, efetivamente, tirar as conseqüên- cias do levante dos escravos de Santo Domingo para sua própria história ${ }^{2}$.

$\mathrm{O}$ mundo em geral e as ciências humanas em particular parecem resistir a aprender com os acontecimentos no $\mathrm{Haiti}^{3}$. Aprendemos com a revolução francesa, com a independência norte-americana e até com aquelas crioulamente realizadas na América Latina, mas fomos e somos incapazes de olhar para o que aconteceu em Santo Domingo entre 1791 e 1804 . Da mesma forma, o pensamento filosófico deteve seu ritmo diante do terremoto de Lisboa de 1755 e reviu suas gloriosas previsóes em torno do progresso e da civilização ${ }^{4}$. Parece que optamos por negligenciar os efeitos do terremoto de 12 de janeiro de 2010 no Haiti à esfera cômoda de uma "catástrofe natural" ou, pior, resultado da incapacidade de ação de um país miserável, desorganizado e corrupto. Tendo como ponto de partida uma etnografia dos dias que sucederam aos terremotos que, no dia 12 de janeiro de 2010, destruíram parte de Porto Príncipe e seu entorno, pretendemos enfrentar, de um lado, o racismo que, sob outras vestes, se manifesta quando se trata de enfrentar a situação contemporânea do Haiti; e de outro, recuperar a reação de haitianos e haitianas que se negam, como sempre se negaram, a assumir a condição de vítimas passivas.

\section{II - Observaçáo e vivência da catástrofe ${ }^{5}$}

Não são usuais os momentos em que o pesquisador compartilha quase tudo aquilo que 
diz respeito aos seus interlocutores em campo: privação, medo, ansiedade; embora nunca tenhamos, eu e minha equipe, deixado de estar numa situação de privilégio em todo o período pós-terremoto, vivemos uma proximidade com nossos interlocutores nunca antes experimentada.

O impacto destrutivo de um terremoto de tais dimensóes, que transforma o mundo a sua volta em ruínas e deixa um sem fim de mortos, feridos e pessoas em extrema vulnerabilidade, foi rapidamente sucedido por uma ordem que espantava qualquer um que quisesse efetivamente prestar atenção no que se passava a sua volta. Num primeiro momento, a população gritou - a Deus, Bondye; a Jesus, Gezi; às pessoas, me zanmi; algumas entraram em transe, incorporando seus respectivos loas ${ }^{6}$; o choro, os prantos e a correria foram intensas: uns fugiam de medo, outros já começavam a socorrer as vítimas, outros iam ao encontro dos seus ou davam início a uma marcha que não parecia ter destino definido. Os gritos e o choro pareciam querer chamar a atenção do mundo sobre si, num processo que cresceu nos dias posteriores a catástrofe. A reação foi oposta àquela observada no país Mapuche, sul do Chile, no último tremendo terremoto de 27 de fevereiro de 2010: diante do terremoto, os Mapuche não correram e não gritaram, antes paralisaram-se, silenciaram-se, pois a energia depreendida pela terra em um terremoto exige que os seres humanos guardem-na ${ }^{7}$. Portanto, não há nem grito, nem choro e as pessoas devem permanecer quietas e esperar. Devem procurar e concentrar a energia que possuem dentro de si. Da mesma forma, os Mapuche parecem não procurar a multidão: a força do terremoto exige uma sorte de introspecção.

O que observamos em Porto Príncipe foi, justamente, a busca da multidão. $\mathrm{O}$ terremoto foi no fim da tarde, a noite se anunciava e as pessoas começaram a correr em direção aos seus; muitas vezes a tarefa era impossível: a destruição era enorme e a comunicação impossível naquele momento em que as ruas estavam intransitáveis e irreconhecíveis. Muitos trataram, assim, de permanecer ali onde o apoio da coletividade se anunciava e, em meio a mortos e feridos, começaram a surgir os primeiros conglomerados que deram origem, em menos de um dia, aos campos de refugiados que, em grande medida, permanecem até os dias de hoje. Nestes conglomerados o grito e o choro foram sucedidos por cânticos coletivos, palmas e danças. E diante de cada novo tremor, os gritos cresciam e as palmas e as danças também.

Nos dias que se sucederam não observamos o caos e muito menos a violência anunciada pela mídia: o que sim observamos foi uma organização tremenda, nos pequenos acampamentos improvisados em ruelas e naqueles imensos que se apropriaram das praças da capital. Rapidamente começaram a chegar produtos alimentares pelas dame sará, mulheres comerciantes que mantinham a distribuição de gêneros básicos que, pelo menos nos dias imediatamente posteriores, mantiveram seus preços mais ou menos estáveis. Havia verduras, arroz, galinha e espaguete e os fogôes eram mantidos a carvão vegetal e comidas preparadas e vendidas no chyenjanbe ${ }^{\text {. }}$.

Rapidamente as associações de moradores, as profissionais e as religiosas, os núcleos estudantis e as organizaçóes locais deram início aos kombits, mutirões para preparo e distribuição de alimentação e, sobretudo, para a procura dos mortos e o socorro dos que estavam entre os escombros e feridos. Não houve espera da atuação da MINUSTAH $^{9}$ ou das organizaçóes internacionais presentes no país que, por outro lado, não vieram. Para nós, foi ficando evidente que a população haitiana estava abandonada. Tínhamos notícia de que a MINUSTAH trabalhava no que restara dos hotéis Cristoph e Montana, onde parte da elite da ONU vivia ou fazia reunióes e intermináveis seminários. Mas, na cidade, no centro, 
em Bel Air, e nos bairros mais atingidos, nada. Onde estava a ONU, ki kote MINUSTAH? - era a pergunta que nos fazíamos. Pouco a pouco percebemos que só nós fazíamos esta pergunta, pois a população não clamava pela MINUSTAH ou pelas organizaçóes internacionais. Parecia haver uma clara consciência de que, diante das dificuldades de qualquer tipo, os brancos, blan $y o^{10}$, são os primeiros a desaparecer. A relação que se estabelece entre o grosso da população e o mundo dos brancos, moun blan, é uma relação de exterioridade quase que total.

\section{III - O fracasso da cooperação ou "eles são assim..."}

Por que fracassou a cooperação internacional? Pela força do terremoto? É fato que as estruturas da cooperação, ONU incluída, foram duramente afetadas pelo sismo. $\mathrm{O}$ fracasso imediato exige, contudo, outras explicaçôes. Destacamos inicialmente a ignorância. Os agentes da comunidade internacional, ou sua esmagadora maioria, ignoram efetivamente o Haiti e os haitianos. O ponto de partida (e o de chegada) de sua atuação é geralmente constituído por uma série de lugares comuns sobre como "eles", os haitianos são desorganizados, dependentes, caóticos e perigosos. Parte da ignorância se revela ainda no fato de a esmagadora maioria dos cooperantes e da imprensa internacionais estabelecidos no país não fala nem compreende o créole $^{11}$, única língua efetivamente falada e compreendida pela totalidade dos haitianos ${ }^{12}$. Sua compreensão da realidade haitiana é forçosamente limitada e condicionada por intermediários (os facilitateurs) ou membros da elite haitiana, conhecedores do francês, do inglês ou do espanhol (e atualmente até do português), eles mesmos interessados na veiculação de determinadas informaçôes sobre o Haiti e os haitianos. As afirmaçóes generalistas e conclusivas sobre o caráter haitiano, quase que universais entre os cooperantes, o corpo diplomático e os empresários estrangeiros estabelecidos no país, estão longe de ser produto de uma vivência real com os haitianos, mas trata-se de representaçôes, produto de suas relações com setores específicos e interessados da sociedade haitiana.

É recorrente e irritante a facilidade com a qual qualquer estrangeiro estabelecido no país há alguns meses ou há alguns anos - recorre a determinadas referências e imagens para explicar como "eles são". Entre as imagens frequentes, a sem dúvida mais exasperante é a que explora a ideia de marronage - interpretada como uma reação marcada por um certo mutismo por parte dos haitianos diante do Estado ou dos estrangeiros e que deitaria raízes no mundo colonial, como se existisse um "ser haitiano" resistente à história ou ao inusitado. O marronage é interpretado como parte de uma espécie de "caráter nacional”, que explicaria parte dos fracassos haitianos - político, econômico, cultural etc.: os haitianos agiriam diante do Estado e da sua violência, ou diante das transformaçóes, da mesma forma que outrora teriam agido diante do senhor de escravos... ${ }^{13}$

Como costuma acontecer, a ignorância leva ao medo: os haitianos no seu dia a dia são percebidos pelos estrangeiros como sumamente perigosos e o Haiti como um país violento. Não há indicadores no Haiti e geralmente as informaçóes veiculadas pela mídia internacional e pelos cooperantes têm como base rumores que jamais são comprovados. Fala-se de roubos, assassinatos e violaçóes sem nenhum tipo de verificação. Não que não existam: é claro que no Haiti há todo o tipo de violência - como em todas as partes. Mas certamente muito menos do que é afirmado de boca em boca pelos membros da comunidade internacional ou por setores da elite haitiana.

A ignorância e o medo não fazem mais do que alimentar o que prevalece em grande medida na 
relação entre os estrangeiros e os haitianos, e que está para além da consciência e da sua bondade ou maldade: o racismo. Comportamentos, reações, limites e expectativas são associados a características inatas de haitianos e haitianas, cuja singularidade se expressa no corpo. Eles são assim, no limite, porque são negros.

Nos dias posteriores aos terremotos, sabíamos da presença cada vez mais significativa de cooperantes estrangeiros no aeroporto de Porto Príncipe, rapidamente controlado pelas tropas norte-americanas. Ao mesmo tempo, tínhamos notícia da evacuação de um grande número de estrangeiros. No aeroporto, a chegada de avióes com contentores era contínua. Mas nos primeiros dias, decisivos para salvar indivíduos sob as ruínas, a ajuda permaneceu encerrada. Por que, nos perguntávamos? A cooperação partia do princípio do caos e imaginava a capital haitiana e as cidades de arredores imersas na violência. Os cooperantes não podiam circular com segurança. Esta suposição manifestou-se fatal para milhares de haitianos que morreram sob os escombros, enquanto uma população desesperada tentava, com suas próprias mãos, salvar seus parentes e amigos.

\section{IV - O kombit e o lakou}

Rapidamente a população se organizou para atender as vítimas da catástrofe. Mas, de que forma? As associaçóes mostraram-se decisivas. Ao contrário do que imaginam aqueles que se aferram ao lugar comum da desorganização inerente ao Haiti contemporâneo, o associativismo neste país é impressionante. Em qualquer povoado, assim como em qualquer bairro da capital, há uma associação de camponeses ou moradores. Saliente-se que, muitas vezes, estas associaçóes disputam recursos com a cooperação internacional e sempre saem derrotadas quando, na prática, são as que de fato funcionam. Nos dias posteriores ao terremoto, foram as associaçóes de moradores, as profissionais, as estudantis e as religiosas aquelas que certamente se mobilizaram para atender os feridos e tentar resgatá-los dos escombros. Sem meios, sem os instrumentos necessários - que estavam no aeroporto.

Qual o princípio do funcionamento destas associaçóes? Entre as palavras que mais escutamos nos dias posteriores ao terremoto, destaco o termo kombit ${ }^{14}$. A tradução para o português do Brasil é relativamente simples - "mutirão", algo assim como trabalho coletivo ${ }^{15}$. Mas o kombit é regido por regras: todos devem participar, porque todos se conhecem. Num bairro há kombit pelos e para os habitantes do bairro; os estudantes fazem kombit para ajudar seus camaradas presos nos escombros; as mulheres fazem kombit para preparar os alimentos. Podemos descrever o kombit como um sistema de prestaçóes e contraprestaçôes que, transferido dos espaços rurais haitianos para a capital, ganha sentido em momentos de crise como aqueles dos terremotos de janeiro de 2010.

O que rege o kombit são, sobretudo, os princípios do lakou, instituição que podemos dizer, sem medo, constitui o núcleo duro da dinâmica de relaçóes no Haiti dos dias que correm ${ }^{16}$. Ao contrário dos que imaginavam o desaparecimento do lakou numa cidade como Porto Príncipe, nos dias posteriores ao terremoto, podemos dizer que vimos o lakou em funcionamento ${ }^{17}$. Quais os princípios do lakou?

Cortesia: um dos princípios do lakou é a cortesia e, fora os primeiros instantes de desespero, os dias seguintes foram marcados pela cortesia. As pessoas, em meio ao medo e à angústia, se ajudavam, se cumprimentavam. As pessoas solicitavam ajuda seguindo regras regidas por dois conceitos chave da civilização haitiana: honné e respé - honra e respeito. A cortesia aqui traduz civismo.

Gênero: rapidamente, as relaçóes de gênero ganharam força impressionante e tarefas foram separadas entre homens e mulheres. Os homens trabalhavam nos escombros, as mulheres na dis- 
tribuição dos produtos e preparação dos alimentos. Todos, no socorro médico.

Faixa etária: o lakou só faz sentido quando organizado cuidadosamente mediante faixas etárias. Os homens mais velhos organizavam os kombits e os jovens se lançaram às ruas no trabalho nos escombros: um trabalho duro, perigoso, sem luvas, sem nenhum tipo de aparelhagem adequada.

Parentela: o lakou garante a inexistência do anonimato, mesmo numa cidade como Porto Príncipe: todos são filhos ou parentes de alguém; ou todos são compadres ou comadres; ou todos são vizinhos ou amigos: as relaçóes se consanguinidade ou de aliança formal são extremamente poderosas. A ideia da generalização de crianças abandonadas, para além dos momentos iniciais após os terremotos, é absurda, pois a maioria foi incorporada pela dinâmica do lakou.

Território: foi o lakou, que possui uma territorialidade específica e transborda as fronteiras de uma localidade, uma cidade ou mesmo nação, que realmente socorreu a população abandonada. Nos dias posteriores ao terremoto, mais de meio milhão de haitianos abandonaram a capital e rumaram, com dificuldade, para regióes distantes do país, dirigindo-se a lugares onde a cooperação internacional não chega ou é absolutamente incipiente. Iam para a casa de parentes e amigos e ali seriam protegidos. E não só: parentes saíram de povoados longínquos e se dirigiram à capital com produtos para socorrer os seus, num momento de angústia, onde as comunicações estavam interrompidas. Da mesma forma, diante do colapso do sistema bancário e da Western Union, membros da diáspora se deslocaram ao Haiti com dinheiro no bolso. $\mathrm{Na}$ falta de voos para Porto Príncipe, as passagens dos EUA e do Canadá para Santo Domingo rapidamente se esgotaram, a fronteira terrestre dominicana-haitiana colapsou nos dois sentidos: no sentido daqueles que queriam abandonar o país e no dos que vinham de longe para trazer comida, remédios e dinheiro para parentes e amigos.

\section{V - Mercados, elites e desigualdade}

O que melhor funcionou nos dias posteriores aos terremotos foi, sem sombra de dúvida, o mercado. Evidentemente não o mercado das lojas ou supermercados, em ruínas ou colapsados, mas aqueles que, já lembrava Sidney Mintz (1959; 1961a; 1961b; 1971; 1974a; 1974b) em seus trabalhos clássicos, parecem mobilizar os haitianos e, em particular, as haitianas ${ }^{18}$. Com efeito, as dame sará, mulheres comerciantes já descritas para o mundo rural por autores como Mintz ou Bastien, controlavam a distribuição dos produtos de primeira necessidade e os vendiam: verduras e galinhas, que vinham do interior ou da República Dominicana, e produtos como espaguete, arroz, óleos, caldo, feijão e sabão. Com extrema dificuldade e muitas vezes precariamente, as pessoas não pararam de se alimentar, de se lavar e de lavar suas roupas. É importante destacar que a esmagadora maioria dos haitianos não guarda seus poucos gourdes (moeda nacional) em bancos, mas em seus bolsos: uma das regras do mercado de rua haitiano é a constante circulação de dinheiro, por pouco que seja, o que garantiu, pelo menos para alguns, o acesso a determinados bens de primeira necessidade nos primeiros dias, enquanto esperavam a ajuda que viria do lakou.

$\mathrm{E}$ as elites haitianas? Se é verdade que o elegante subúrbio de Pétionville foi menos atingido - pela melhor qualidade das construçóes e por se encontrar na subida da alta montanha que se sobrepóem à capital - a verdade é que muito também foi destruído e muita gente morreu. Os que podiam, mais ricos, procuraram deixar o país nos dias seguintes, pois quase todos têm parentes nos Estados Unidos, França e Canadá. Mas boa parte permaneceu e mobilizou seus recursos para ajudar os seus parentes e os seus amigos, numa dinâmica curiosa que confirmava, entre os mais favorecidos, o próprio lakou. Mas os mais ricos tiveram um comportamento 
semelhante ao dos cooperantes, que chamo de "colonial": atuaram pela lógica de um cerco, permanecendo em seus bairros fechados, temiam a violência da cidade e pouco sabiam o que estava realmente acontecendo em Porto-Príncipe e arredores diante do colapso da TV e dos rádios ${ }^{19}$.

A reprodução da desigualdade manifestou-se mais e mais nos meses que se sucederam à destruição. Recolher o entulho, por exemplo, foi entregue a companhias privadas. Assim, alguém que teve sua casa destruída tinha que recorrer a uma empresa, que possui máquinas, caminhóes e trabalhadores, para a remoção dos escombros por somas que chegam a milhares de dólares americanos, dependendo da quantidade. Membros de elites abastadas que perderam suas casas, ou qualquer um que tivesse algum recurso disponível ou um parente na diáspora disposto a ceder este recurso, podiam remover os escombros e começar a reconstrução de sua nova casa $^{20}$. Os mais pobres, ou estão em campos de refugiados, ou vivem em meio, diante ou sobre os escombros.

A relação com os escombros parece redefinir em grande medida a desigualdade social haitiana: os mais pobres "se viram" e arrancam dos escombros tudo o que é passível de ser vendido no mercado voltado à reconstrução, como os ferros das estruturas, por exemplo. É difícil arrancar os ferros dos escombros e depois de arrancá-los, você pode vendê-los torcidos, como os encontrou, ou retos, o que exige horas e horas de trabalho, o que reflete no preço final. Formaram-se mercados imensos de ferro e entulho; é dali que sai a reconstrução, não da ajuda internacional ${ }^{21}$.

\section{VI - O Estado existente: fragmentos, memória, saudade, desejo}

É recorrente o lugar comum segundo o qual o Estado é inexistente no Haiti. Esta mera afirmação parece explicar o estado de pobreza anterior ao terremoto, o desespero de bondosos cooperantes que chegam num país de por si caótico, a suposta violência onipresente e o suposto caos posterior ao terremoto. O fracasso do Estado no Haiti fez com que alguns antropólogos, como Gérard Barthélemy (1989), comparassem este país a "sociedades contra o Estado", numa inadequada analogia com as sociedades tupi descritas por Clastres (2003). No extremo oposto ao romantismo de Barthélemy, temos os hobbesianos de plantão, cuja a afirmação da inexistência de Estado entre os primitivos da América ou da África os fez ver lobos devorando-se entre si em terríveis rituais antropofágicos. Ei-los aqui outra vez, afirmando ser o Haiti uma sociedade sem Estado, e, portanto, caótica - nunca saberemos se é caótica porque não tem Estado ou se não tem Estado porque é caótica $^{22}$. Trata-se, enfim, de uma simples tautologia, que não faz justiça ao pensamento hobbesiano e, sobretudo, não respeita a particularidade histórica que compreendeu a formação do Estado haitiano. Dois autores são interessantes aqui: o antropólogo haitiano Michel-Rolph Trouillot (1990) e o cientista social ugandense Mahmood Mandani (1996). O primeiro, partindo do próprio Haiti, e o segundo, tendo como referência contextos africanos, pretendem compreender os Estados em sua particularidade histórica, a partir de um conjunto de elementos positivos e não por meio do que ele não é.

No caso do Haiti, impóem-se a dura tarefa de compreender como se construiu o Estado haitiano - entre a herança do Estado colonial francês, o duro ostracismo ao longo do século XIX, a ocupação americana, uma modernização sui generis e, por fim, a lógica da guerra fria que se impôs na parte ocidental da ilha de Santo Domingo como em nenhuma outra parte por meio da ditadura particularmente cruel do clá Duvalier (Diedrich et Al Burt, 1986; Trouillot, 1990). Ou seja, o Estado existe no Haiti, foi construído e parcialmente destruído: o Estado está lá, presente na forma de fragmentos, na for- 
ma de memória ou como desejo ou expectativa. O Estado está, enfim, na cabeça de todos os haitianos, bem como em instituiçóes que, mal ou bem, são as haitianas; e no dia-a-dia.

Impostos locais são pagos nos mercados que reúnem populaçóes de povoados distantes; o barco de Jérémie não parte para Porto-Príncipe sem autorização da chefatura dos portos; funcionários de província se dirigem à capital quando os recursos não são devidamente transferidos; nos locais de saída dos tap-taps seus donos pagam impostos a responsáveis locais; há autoridades que emitem passaportes e controlam a entrada e a saída do país; há polícia. As elites haitianas afirmam que pagam impostos - donos de lojas, responsáveis pela importação e pela circulação de bens nos mercados (Cf. Thomaz, 2005). Certamente há uma imensa evasão fiscal e nos momentos de crise, que têm sido muitos, os mecanismos nacionais são paralisados. E com toda a certeza há um alto grau de corrupção e obras públicas não são levadas adiante - outras contudo foram, sim, feitas nos últimos anos. Mas daí a afirmar-se a inexistência de Estado temos um grande passo.

Quem ignora o Estado haitiano não são os haitianos que votam em cada eleição e que vão às ruas quando se sentem defraudados. Os que ignoram o Estado haitiano são os que se negam a com ele colaborar, garantindo assim a continuidade de um processo de dilapidação que tem várias direçôes. Refiro-me evidentemente à comunidade internacional, entre os bem-intencionados cooperantes que trabalham nas ONGs, os cínicos funcionários da $\mathrm{ONU}$, as tropas da MINUSTAH, um medíocre corpo diplomático estabelecido neste país e comerciantes inescrupulosos que, em conjunto com os Estados Unidos, promoveram a abertura quase que total das fronteiras haitianas, provocando crises como as da produção do milho e, sobretudo, do arroz, cruciais para compreender os limites produtivos do Haiti nos dias que correm ${ }^{23}$.
E o Estado existe na memória: faz parte da conversa de haitianos e haitianas urbanos a memória de um período onde o Estado se fazia presente nas cidades, mantinha o bord-de-mer de Porto-Príncipe limpo, bem como o magnífico Marché en Fer. Sem sombra de dúvida, tratava-se de um Estado bifurcado, para usar um termo de Mamdani (1996), mas ainda assim Estado: que promovia um tratamento diferenciado para aqueles habitantes da cidade e que se encontravam no seu próprio aparelho, ou para os comerciantes, haitianos - entre negros, mulatos e sírio-libaneses - e estrangeiros, de um lado, e a esmagadora maioria camponesa rural, do outro. Um Estado que falava francês, reproduzia os padróes ditos ocidentais de comportamento, e reprimia, quando podia, violentamente a prática do vodu e ostracizava a língua haitiana. Mas ainda assim Estado.

A memória dos camponeses também faz referência ao Estado, que os mantinha na miséria por meio de taxas abusivas sobre produtos como o café, que procurava controlar seus mercados, que se expressava numa língua desconhecida que lembrava seus antigos senhores franceses contra quem tinham lutado. Mas mesmo assim um Estado que procurava garantir a segurança nas poucas vias existentes e que se apoiava no caráter conservador do próprio lakou para garantir seu funcionamento: respeitava-se o Estado como se respeitava um pai, com quem não se conversava e que não se ousava mesmo a mirar diretamente aos olhos. Um Estado que garantia seu poder por meio de frágeis alianças com senhores locais, não muito diferente daquele descrito para o Brasil dos coronéis ou para a América Hispânica dos caudilhos. Mas um Estado que, autoritário ou não, fazia valer a ordem e o respeito.

O Estado surge ainda como demanda, como expectativa: não estamos entre os Nuer (Evans-Pritchard, 1981) que desconheciam o Estado ${ }^{24}$, ou os Tupi que parecem conhecê-lo e pretendem evitá-lo (Clatres, 2003): o Estado é desejo. 
Após a queda de Duvalier (1986), vota-se sempre que possível; teme-se cada golpe; espera-se alguém que, do Estado, faça alguma coisa ${ }^{25}$. E os que estão no Estado fazem alguma coisa. Quando não fazem, tudo se paralisa. Nos meses posteriores a janeiro de 2010, o Estado haitiano caiu literalmente por terra: o Palácio Nacional se transformou em ruínas e praticamente todos os ministérios deixaram de existir. Concomitantemente, as províncias não paravam de receber refugiados - cidades de 20.000 habitantes viam-se transformadas em campos de 40.000 . Instituições localizadas nas províncias suspenderam suas atividades, pois não vinham ordens de Porto-Príncipe. Nem ordens, nem salários dos funcionários públicos. Salários recebidos esporadicamente, mas ainda assim recebidos, e que lhes dá crédito. Os terremotos pareceram jogar a todos numa incerteza tal que não havia nada a ser feito além de paralisar suas atividades: professores e alunos não iam às aulas, prefeituras e secretarias locais fecharam suas portas, cobradores locais de impostos não sabiam o que fazer ${ }^{26}$. A província, inicialmente não tocada pela violência destruidora do terremoto, perdeu sua capital e, portanto, sua centralidade estatal: diante deste quadro, dizer que o Estado não existe no Haiti é, no mínimo, fruto de preguiça empírica, e no máximo, consequência da leviandade à qual parecem estar condenados os haitianos.

\section{VII - Consideraçóes finais}

Todos os que, entre historiadores e antropólogos, nos debruçamos sobre o Haiti, temos que enfrentar uma espécie de embargo secular que, tão bem descrito pelo antropólogo haitiano Michel-Rolph Trouillot (1995), faz parte da própria história intelectual haitiana. Independente da discussão sobre o caráter supostamente impensável da revolução, intelectuais haitianos em distintos momentos da história deste país e da diáspora depararam com uma espécie de ostracismo que lhes parece negar um lugar no mundo ${ }^{27}$. É fascinante encontrarmos uma obra como a de Antenor Firmin quem, poucos anos após da publicação do clássico de Gobineau, Sobre a desigualdade natural das raças humanas, publica seus volumes De l'egalité des races humaines (2004 [1885]), nos quais apela para a antropologia de Kant e para o conhecimento acumulado ao longo do século XIX com o propósito de demonstrar o caráter absurdo, ideológico e a-científico das teorias raciais que dominavam a inteligentsia europeia e americana de então. Firmin, antropólogo haitiano, deveria ser reivindicado como um dos pais da antropologia moderna, mas sua obra permaneceu desconhecida fora do seu país e só ganhou uma tradução para o inglês no ano 2000, 120 anos depois.

Nega-se a possibilidade de uma civilização haitiana e, na contemporaneidade, não são poucos os que fazem exercício da sua ignorância e afirmam a incapacidade haitiana para a reconstrução do seu país. É como se a crise atual não fosse mais do que a evidência da incapacidade de outrora. Não são poucos os que se apressam a afirmar a inexistência de Estado no Haiti e o estado de caos no qual vivem. A crise não é percebida como produto de uma história, que merece ser investigada, mas como a comprovação daquilo que há muito se sabe. Podemos nos esgoelar: o Haiti já foi um país normal, não era muito diferente dos demais países do Caribe, e foi responsável por um projeto de superação único no continente. Geralmente, a reação diante da tentativa de ir além de um lugar comum sobre o Haiti se enfrenta a condescendência que anula seu possível caráter público, crítico e propositivo e se vê enjaulada sob a rubrica do pitoresco. Por quê?

No segundo dia após o primeiro grande terremoto, quando caminhava no centro da cidade em meio à multidão, escutei jovens com alto-falantes solicitando ajuda para tirar seus colegas 
sob os escombros da Faculdade de Linguística Aplicada da Universidade de Estado. Hoje sabemos que, dos 500 estudantes de linguística, pereceram cerca de 350; das 250 estudantes de enfermagem, morreram 190 , e por aí vai ${ }^{28}$. Neste momento imaginei que minha única contribuição poderia ser junto ao ensino superior, campo no qual trabalho em meu país. Poderia tentar envolver estudantes brasileiros e haitianos no esforço de produzir um retrato do impacto do terremoto junto às instituiçôes de ensino superior no Haiti e, assim, promover uma política que pudesse efetivamente ajudar uma importante instituição central em qualquer espaço nacional contemporâneo. No Haiti temos universidades e instituiçóes de ensino superior. E, apesar de todas as crises das últimas décadas, as universidades nunca pararam, e garantiram a renovação de geraçóes de profissionais não só alimentaram necessidades do Haiti, mas forneceram quadros para outros países, com destaque para Canadá, Estados Unidos e países francófonos africanos (Nascimento, 2011: 21). Com o terremoto, pela primeira vez em 150 anos, estas instituições pararam e não têm perspectiva de retomar seu funcionamento. Estudantes, professores e funcionários têm se visto impedidos de retomar, os prédios que não caíram, estão colapsados; e muitos professores e alunos morreram.

Quando expressei minha ansiedade diante de um quadro de precariedade extrema que parece condenado a se reproduzir nos próximos tempos, me surpreendi com a reação de alguns colegas. Afinal, os haitianos não precisariam de universidades, ou bibliotecas: precisariam de água e comida. Ora, em 1945, quando os alemães caçavam ratos pelas ruas de Berlim, e antes mesmo do início do Plano Marshall, os Estados Unidos tomaram a sábia decisão de, rapidamente, reerguer a Biblioteca Estatal. Os recursos foram infinitos, e não apenas se reergueu a Biblioteca Estatal, como se ofereceram recursos para a construção da que é hoje uma das maio- res bibliotecas europeias. Da mesma forma, a Filarmônica de Berlim entrou em rápido funcionamento. Insisto: os alemães comiam ratos e dormiam nas ruas. Mas a conclusão óbvia é que qualquer esforço de reconstrução europeia passava pela reconstruçáo de seu patrimônio, material, artístico e intelectual.

O terremoto não foi uma catástrofe natural. Seus efeitos foram socialmente produzidos da mesma forma que uma guerra ou uma bomba. Em Porto-Príncipe, Jacmel, Léogâne, Petit-Goâve e Grand-Goâve perdeu-se uma quantidade inestimável de indivíduos - fala-se em 250.000 mortos. Para além dos feridos, o número de refugiados chegou a cerca de um milhão e meio de almas. Em Porto-Príncipe foram abaixo escolas, universidades, bibliotecas e prédios históricos. Léogâne, cidade de extraordinário valor histórico, epicentro do terremoto, deixou de existir. E se há uma coisa que os haitianos, todos e cada um deles, têm imenso orgulho é da sua história e dos seus heróis. O terremoto já foi incorporado na história do Haiti: há um "antes" e um "depois”. Como há um "antes" e um "depois" da ocupação americana, da ditadura do clã Duvalier, do Coup d'État. O Haiti é um país de história, a qual foi ignorada e jogada no ostracismo nos últimos duzentos anos.

E por quê? Estou convencido que os antropólogos devem se enfrentar a adversários antigos, que nos acompanham desde os primórdios da disciplina, e que, no passado com uma roupagem científica e ora disfarçados do politicamente correto ou na vestimenta da ajuda internacional, continuam acreditando no sentido da raça. Afinal, os haitianos são quase todos negros. Como um país de negros ousa querer revelar alguma coisa ao mundo e afirmar a lembrança de fatos que ocorreram há mais de dois séculos?

As elites haitianas, incapazes de promover efetivamente um ciclo virtuoso e claramente emancipador, são culpabilizadas pelo fracasso do país; o haitiano urbano é transformado num 
potencial violento ou num habitante de um mundo anômico, que subsiste de migalhas, e o camponês, condenado a uma miséria já anunciada por aqueles que, no século XIX, queriam reintroduzir o regime de grande propriedade no país, e que tentaram reintroduzi-lo inviabilizando uma e outra vez a produção familiar. Os haitianos de todos os grupos sociais transformaram-se em objeto de discursos e políticas, jamais sujeitos, mesmo quando o terremoto revela o fracasso de um mundo que os brancos inventaram por ali, o mundo da ajuda internacional. Tudo isto, insisto, porque são negros.

\section{Notas}

1. As reflexôes que ora seguem foram construídas em diálogo com colegas e amigos. Agradeço assim a Berhman Garçon, Diego Nespolón Bertazzoli, Federico Neiburg, Jean-Phillpe Belleau, Joanna Da Hora, Natasha Nicaise, Otávio Calegari e Rodrigo Bulamah. Sebastiâo Nascimento, muitas vezes a contragosto, é meu interlocutor privilegiado. O que segue é, entretanto, de minha inteira responsabilidade.

2. Sobre o lugar da revolução haitiana e o ostracismo ao qual foi relegada ver o trabalho do antropólogo haitiano Michel-Rolph Trouillot (1995). Para uma reação à proposta de Trouillot, ver Tomich (2009). Um trabalho fascinante é o da filósofa Susan Buck-Morss (2011), que revela a importância (negligenciada pelos comentadores) da revolução haitiana nas reflexôes de Hegel que culminaram na dialética do senhor e do escravo.

3. Não deixa de ser inquietante, como lembra Michel-Rolph Trouillot, que Eric Hobsbawm - escritor insuspeito e progressista - dedique em seu $A$ era das revoluçôes apenas uma nota de rodapé à revolução haitiana Cf. Trouillot, 1995; Hobsbawm, 1999.

4. Não foram poucos os filósofos que fizeram referência ao terremoto de Lisboa, com destaque para Voltaire em seu Candide, bem como no "Poème sur le désastre de Lisbonne”, cuja reflexão sobre a catástrofe de 1755 é recuperada posteriormente por Theodor Adorno. Para Adorno, da mesma forma que o terremoto, o holocausto teria um impacto decisivo e transformador na cultura e filosofia européias. Sobre o pensamento filosófico e o terremoto de Lisboa ver, entre outros, José-Augusto França (2008).
5. No momento do terremoto encontrava-me com minha equipe de pesquisa em Porto Príncipe. Faziam parte da equipe Cris Bierrenbach, Diego Nespolón Bertazzoli, Joanna Da Hora, Marcos Pedro Magalhães, Otávio Calegari e Rodrigo Bulamah . A pesquisa contava com o apoio do CNPq e da Universidade Estadual de Campinas. Como resultado desta breve incursão em campo, publiquei, no calor da hora, uma "etnografia selvagem" da catástrofe logo após o nosso retorno (Thomaz, 2010). Tive a oportunidade de, nos meses de novembro e dezembro de 2010, retornar ao Haiti com a companhia insubstituível de Sebastião Nascimento.

6. Trata-se dos espíritos do vodu - religiáo praticada no Haiti - e garantem a intermediação entre Bondye e os homens. Sobre o Vodu ver o clássico de Alfred Metraux (1977).

7. Devo as informaçóes sobre as reações dos Mapuche diante de terremotos a José Quindel Lincoleo, pós-graduando em antropologia social pela Unicamp e líder Mapuche, a quem agradeço. José encontrava-se no país Mapuche quando dos terremotos de 2010 e tivemos a oportunidade de discutir nossas observaçôes em mais de uma ocasião.

8. Trata-se de um pequeno restaurante de rua, localizado nas calçadas e geralmente pouco confortável.

9. Mission des Nations Unies pour la stabilisation em Haïti, estabelecida no país em abril de 2004.

10. No Haiti o termo blan é polissêmico: quer dizer ao mesmo tempo "branco" e "estrangeiro".

11. Kreyòl ou ayitien.

12. O francês, língua oficial ao lado do kreyòl, é dominada por uma parcela pequena da população. Trata-se de um signo de distinção daqueles que se consideram parte das elites diante da esmagadora maioria da população (Cf. Thomaz, 2005; Casimir, 2009).

13. O trabalho de intelectuais haitianos de extrema qualidade acaba por corroborar, equivocadamente, a existência de um "caráter nacional". Cf. Laënnec Hurbon (1979; 1987).

14. A centralidade do kombit no universo rural haitiano é salientado na extraordinária etnografia de Remy Bastien (1951). Sobre a hierarquia no universo do lakou rural ver a não menos extraordinária etnografia de Rhoda Metraux (1951).

15. O termo "mutirão" é de origem Tupi e restrito ao português do Brasil, sendo desconhecido em Portugal ou nos Países Africanos de Língua Oficial Portuguesa.

16. O lakou foi considerado por Remy Bastien como instituição central do universo rural haitiano. Grosso modo, o lakou traduz relaçóes marcadas pela consangüini- 
dade e aliança (aliança alargada, que inclui amigos e vizinhos) pautadas por rigorosos princípios morais. A noçâo de société à maison de Lévi-Strauss pode ser útil para compreendermos o lakou, embora não dê conta da dinâmica e das metamorfoses do lakou urbano desafio para o trabalho antropológico no Haiti contemporâneo (Cf. Bastien, 1951; Lévi-Strauss, 1984).

17. Há uma imensa bibliografia sociológica que, a partir dos anos 1970, percebe o aumento populacional ("explosão demográfica”) e a urbanização como responsáveis pelo ocaso dos princípios ordenadores do universo rural haitiano, sem atentar, entretanto para o caráter dinâmico destes mesmos princípios. E aqui se destaca positivamente o trabalho pioneiro de Louis Marcelin (1988). Sobre aqueles que vaticinam o caos e a anomia cf., entre muitos outros, Pierre (1997); Robert Rotberg (1971).

18. Minhas reflexões sobre os mercados no Haiti são absolutamente devedoras de intermináveis e fascinantes conversas que venho tendo nos últimos anos com Federico Neiburg.

19. As elites haitianas constituem um tema clássico no próprio pensamento social deste país. Cf. Jean Price-Mars. (2001 [1919]). Há alguns anos, realizei um trabalho específico junto a grupos de elite de Porto Príncipe e Cabo Haitiano, onde procuro destacar elementos de um comportamento que defini como "colonial" (Thomaz, 2005). Recentemente, Jean Casimir (2009) retomou esta temática clássica do pensamento haitiano.

20. Os recursos da diáspora, antes destinados, entre outras coisas, à manutenção de jovens estudantes nas escolas e universidades haitianas (o ensino no Haiti é todo pago), foi completamente canalizado para o auxílio da reconstruçáo, o que na maioria das vezes significou a interrupçáo dos estudos de jovens haitianos.

21. Esta informação preciosa se deve à observação cuidadosa de Sebastiáo Nascimento.

22. A produção sobre o caos haitiano é gigantesca, e vai das ciências sociais a trabalhos jornalísticos ou de divulgaçấo. Destaco o trabalho de Chistophe Wargny (2008) que, sofisticado, incorre na mesma narrativa. Para uma visão crítica deste tipo de reflexão recorrente ver Felipe de Andrade Silva Evangelista (2010).

23. Sobre as conseqüências das políticas econômicas seguidas no Haiti ao longo dos anos 1990, e a crise contemporânea, particularmente a crise do arroz, ver o texto de Peter Hallward (2004).

24. O desconhecimento Nuer do Estado deve ser revisto diante de extraordinárias mudanças históricas ( $\mathrm{Hu}$ tchinson, 1996) e da recente fundaçáo do Sudâo do Sul.
25. O Estado é percebido como um direito (Thomaz, 2005).

26. Entre novembro e dezembro de 2010, visitamos todas as capitais departamentais haitianas. Todos foram unânimes ao afirmar que a destruição de Porto-Príncipe representou a paralisação de quase todas as atividades ao longo de meses.

27. As referências a esta falta de lugar do mundo não se restringe à produção intelectual haitiana, mas se espraia em narrativas de haitianos e haitianas de distintos grupos sociais.

28. Sobre o impacto do terremoto no sistema de ensino superior haitiano, suas perdas materiais e humanas, ver o trabalho de Sebastião Nascimento (2011).

\section{Referências bibliográficas}

BARTHÉLEMY, Gérard. Le pays en dehors: essai sur l'univers rural Haitien. Porto-Príncipe: Henri Deschamps, 1989.

BASTIEN, Remy. La familia rural haitiana. Valle de Marbial. México: Libra, 1951.

BUCK-MORSS, Susan: "Hegel e Haiti". In: Novos Estudos Cebrap. Sáo Paulo: Cebrap, julho de 2011, n 90 : 131-172.

CASIMIR, Jean. Haïti et ses élites. Porto-Príncipe: Editions de l'Université d'État d'Haïti, 2009.

CLASTRES, Pierre. A sociedade contra o Estado. São Paulo: Cosacnaify, 2003.

EVANGELISTA, Felipe de Andrade Silva. Construçöes do "fracasso" haitiano. Rio de Janeiro: Dissertação de mestrado, PPGAS - UFRJ, 2010.

EVANS-PRITCHARD, Evans: "Os Nuer do Sul do Sudão”. In: Fortes, M. \& Evans-Pritchard, Evans. Sistemas politicos africanos. Lisboa: Fundaçáo Calouste Gulbenkian, 1981, pp. 469-507.

FIRMIN, Antenor. De l'egalité des races humaines 2. Vols. Porto-Príncipe: Collection du Bicentenaire, 2004 [1885].

FRANÇA, José-Augusto. Lisboa. História Física e Moral. Lisboa: Livros Horizonte, 2008.

HALLWARD, Peter. Option zero in Haiti. New Left Review 27, May-June 2004, pp $23-47$.

HOBSBAWM, Eric. The Age of Revolution: Europe: 17891848. Peter Smith Pub Inc, 1999.

HURBON, Laënnec. Cultura et dictature en Haïti. Paris: Harmattan, 1979.

Comprendre Haití: essai sur l'Etat, la nation, la culture. Paris: Éditions Karthala, 1987. 
JUDT, Tony. Postwar: A History of Europe Since 1945. Londres: Penguin, 2006.

LÉVI-STRAUSS, Claude. Paroles Données, Plon, Paris, 1984.

MARCELIN, Louis. La Famille Suburbaine à Saint-Martin, Port-au-Prince, Porto-Príncipe: Faculté d'Ethnologie, Université d'Etat d'Haïti, 1988.

METRAUX, Alfred. Le Vaudou Haitien. Paris: Gallimard, 1977.

METRAUX, Rhoda. Kith and Kin. A Study of Créole Social Structure in Marbial, Haiti. Nova York: Columbia University, 1951.

MINZ, Sidney: "Afro-Caribbeana: An Introduction". In: Caribbean Transformations, Chicago: Aldine Publishing Company, 1974a. Cap. 1: 1-42.

."Caribbean nationhood: an Anthropological Perspective", in Caribbean Transformations, Chicago: Aldine Publishing Company, 1974b. Cap. 11: 302-327.

."Internal Market Systems as Mechanisms of Social Articulation”. In: V.F. Ray (ed.) Intermediate Societies, Social Mobility and Communication. Seattle: University of Washington Press, 1959. Pp. 20-30.

. A tentative typology of eight Haitian market places. Revista de Ciencias Sociales 4: 15-17, 1961a;

."Standards of Value and Units of Measure in the Fond-des-Negres Market Place, Haiti”. The Journal of The Royal Anthropological Institute of Great Britain and Ireland, 1961b,_91(1): 23-38
Men, women and trade. Comparative Studies in Society and History, 13 (3), 1971.

NASCIMENTO, Sebastiẫo (com a colaboração de Omar Ribeiro Thomaz). Da crise às ruinas: o impacto do terremoto no ensino superior no Haiti. Curitiba: Huya, 2011 (no prelo).

PIERRE, Luc-Joseph. Haïti: les origines du chaos. Porto-Príncipe: Henri Deschamps, 1997.

PRICE-MARS, Jean. La vocation de l'Elite. Porto-Príncipe: Presses Nationales d'Haïti, 2001 [11919].

ROTBERG, Robert. Haiti: the politics of squalor, Boston: Houghton Mifflin Company, 1971.

THOMAZ, Omar Ribeiro: "Haitian elites and their perceptions of poverty ando f inequality". In: Reis, Elisa P. \& Moore, Mick. Elite Perceptions of Poverty \& Inequality. Londres e Nova York: Zed Books, 2005: 127-155.

. O terremoto no Haiti, o mundo dos broncos e o lougawou. Novos Estudos Cebrap. São Paulo: Cebrap, março de 2010, n 86: 23-50.

TOMICH, Dale: "Pensando o 'impensável': Victor Schoelcher e o Haiti”. In: Mana. Rio de Janeiro: PPGAS/ Museu Nacional, abril de 2009, vol.15, n.1: 183-212.

TROUILLOT, Michel-Rolph. Silencing the Past. Power and the production of History. Boston: Beacon Press, 1995.

. State against Nation: Origins \& Legacy of Duvalierism. Nova York: Monthly Review Press, 1990.

WARGNY, Christophe. Haïti n'existe pas: 1804 - 2004. Deux cent ans de solitude. Paris: Autrement, 2008.

autor Omar Ribeiro Thomaz

Professor do Departamento de Antropologia Social / Unicamp

Pós-Doutor em Antropologia Social / Max Planck Institute, Halle

Recebido em 06/10/2011

Aceito para publicação em 06/10/2011 